\title{
Chromosome 8q23.3, 10p14 and 11q23.1 variants modify colorectal cancer risk in Lynch syndrome - a combined analysis of the Australian, Dutch and Polish Lynch syndrome cohorts
}

Bente A Talseth-Palmer ${ }^{1,2^{*}}$, Juul T Wijnen ${ }^{3}$, Ingvild S Brenne ${ }^{2,4}$, Shantie Jagmohan-Changur ${ }^{3}$, Katie A Ashton ${ }^{1,2}$, Carli M Tops ${ }^{3}$, Tiffany-Jane Evans ${ }^{1,2}$, Mary McPhillips ${ }^{5}$, Claire Groombridge ${ }^{6}$, Janina Suchy ${ }^{7}$, Grzegorz Kurzawski ${ }^{7}$, The Dutch Cancer Genetics Group ${ }^{8}$, Allan Spigelman ${ }^{9}$, Pål Møller ${ }^{10}$, Hans M Morreau ${ }^{11}$, Tom Van Wezel ${ }^{11}$, Jan Lubinski ${ }^{7}$, Hans FA Vasen ${ }^{12}$, Rodney J Scott ${ }^{1,2,5}$

From Familial Aspects of Cancer 2011 Research and Practice: A combined meeting of kConFab, Australian Breast Cancer Family Study, Australian Colorectal Cancer Family Study, Australian Ovarian Cancer Study, Family Cancer Clinics of Australia and New Zealand and kConFab

Kingscliff, Australia. 23-26 August 2011

\section{Background}

For a decade researchers have been searching for modifier genes in individuals with a molecular diagnosis of Lynch syndrome but the task has proven difficult as discordant results seem to be the rule rather than the exception. Recently, two colorectal cancer (CRC) susceptibility loci have been found to be significantly associated with an increased risk of CRC in Dutch Lynch syndrome patients irrespective of which gene was mutated. In a combined study of CRC risk in Australian and Polish Lynch syndrome patients only MLH1 mutation carriers were found to be at increased risk of disease. A combined analysis of the three datasets was performed to better define this association.

\section{Methods}

The three populations combined totalled 1359 individuals from 425 families with a molecular diagnosis of Lynch syndrome. To date, this represents the largest Lynch syndrome cohort examined for modifier genes. Seven SNPs, from 6 different CRC susceptibility loci, were genotyped by both research groups and the data analysed collectively.

${ }^{1}$ School of Biomedical Sciences and Pharmacy, University of Newcastle, Australia

Full list of author information is available at the end of the article

\section{Results}

Individuals with $M L H 1$ mutations harbouring the CC (variant) genotype of SNP rs3802842 are at increased risk of $\mathrm{CRC}(\mathrm{HR}=2.77, \mathrm{p}<0.001)$ and develop CRC on average 11 years earlier than individuals with the AA (wild type) genotype. All females (MLH1, MSH2 and MSH6 mutation carriers) carrying the CC genotype of SNP rs3802842 are at increased risk of CRC $(\mathrm{HR}=2.16$, $\mathrm{p}=0.005$ ), while female MLH1 mutation carriers are at highest risk $(\mathrm{HR}=3.88, \mathrm{p}<0.001)$.

To investigate whether a cluster of risk alleles increases the risk of CRC, SNP rs3802842 was combined with the other six SNPs additively. MLH1 mutation carriers harbouring 3 risk alleles for SNP combination; rs3802842 (11q23.1) + rs16892766 (8q23.3) display an increased risk of CRC $(\mathrm{HR}=5.67, \mathrm{p}=0.001)$ and an immense difference in the age of diagnosis of CRC of 28 years is observed compared to individuals with 0 risk alleles. While SNP combination; rs3802842 + rs10795668 (10p14) displays an increased risk of CRC for all females harbouring 4 risk alleles $(H R=5.52$, $\mathrm{p}=0.003)$.

\section{Conclusion}

These results confirm the role of modifier genes in HNPCC. We recommend that Lynch syndrome patients with $M L H 1$ mutations and all Lynch syndrome females 
are genotyped for two SNPs in each group so that a personalised risk assessment and tailored surveillance program can be offered to patients at increased risk of CRC and therefore likely to develop their CRCs at much younger ages than the average age of disease onset.

\section{Author details}

${ }^{1}$ School of Biomedical Sciences and Pharmacy, University of Newcastle, Australia. ${ }^{2}$ Hunter Medical Research Institute, John Hunter Hospital, Newcastle, Australia. ${ }^{3}$ Center of Human and Clinical Genetics, Leiden University Medical Centre, Leiden, the Netherlands. ${ }^{4}$ Department of Pharmacology, The Institute of Pharmacy, Faculty of Medicine, University of Tromsø, Norway. ${ }^{5}$ Hunter Area Pathology Service, Hunter New England Area Health, Newcastle, Australia. ${ }^{6}$ Hunter Family Cancer Service, Hunter New England Area Health, Newcastle, Australia. International Hereditary Cancer Center, Department of Genetics and Pathology, Pomeranian Academy of Medicine, Szczecin, Poland. ${ }^{8}$ The Dutch Cancer Genetics Group, the Netherlands. 'University of NSW, St Vincent's Hospital Clinical School, Sydney, Australia. ${ }^{10}$ Section for Inherited Cancer, Department of Medical Genetics, Rikshospitalet-Radiumhospitalet Medical Center, Oslo, Norway. ${ }^{11}$ Department of Pathology, Leiden University Medical Centre, Leiden, the Netherlands. ${ }^{12}$ Dutch Foundation for the Detection of Hereditary Tumours, Leiden, the Netherlands.

Published: 12 April 2012

\section{doi:10.1186/1897-4287-10-S2-A32}

Cite this article as: Talseth-Palmer et al: Chromosome 8q23.3, 10p14 and 11q23.1 variants modify colorectal cancer risk in Lynch syndrome a combined analysis of the Australian, Dutch and Polish Lynch syndrome cohorts. Hereditary Cancer in Clinical Practice 2012 10(Suppl 2): A32.

\section{Submit your next manuscript to BioMed Central} and take full advantage of:

- Convenient online submission

- Thorough peer review

- No space constraints or color figure charges

- Immediate publication on acceptance

- Inclusion in PubMed, CAS, Scopus and Google Scholar

- Research which is freely available for redistribution

Submit your manuscript at www.biomedcentral.com/submit 